\title{
Review of: "The veterinary anti-parasitic selamectin is a novel inhibitor of the mycobacterial DprE1 enzyme"
}

\author{
Patrick Valere TSOUH FOKOU
}

Potential competing interests: The author(s) declared that no potential competing interests exist.

The article tries to describe the antimycobacterial mode of action of selamectin. However, there are few shortcomings that need to be address. The title is misleading as no confirmation was achieved with $\mathrm{M}$. smegmatis mutant strains construct and MIC phenotypic assays performed.

It we be better to briefly introduce the analysis of mycobacterial lipids for metabolic labeling and how it is related to DprE1 inhibition.

In materials and methods, provide the reference number and the origin of each strain use in the study as well as the origin, supplier, country for each reagent

For the time kill kinetic assays, it is not clear to me how long the smegmatis was incubated, 3h. Can you explain the necessity of 3 days pre-incubation period prior to the addition of selamectin? Clearly describe the procedure use for this experiment. For smegmatis, are you saying that selamectine was test at 4 $\mu \mathrm{g} / \mathrm{ml}, 16 \mu \mathrm{g} / \mathrm{ml}, 4 \mu \mathrm{g} / \mathrm{ml}$ and $16 \mathrm{ng} / \mathrm{ml}$ ? Clarify.

Concerning, Construction of M. smegmatis DprE1 point mutants it is still not clear beyond doubt how you ensure the purity of isolated mutants? Provide more details in the manuscript

Check for typos the whole document for typographical errors e.g. @ or $\mu$ 